\title{
Seccionce
}

Sección central

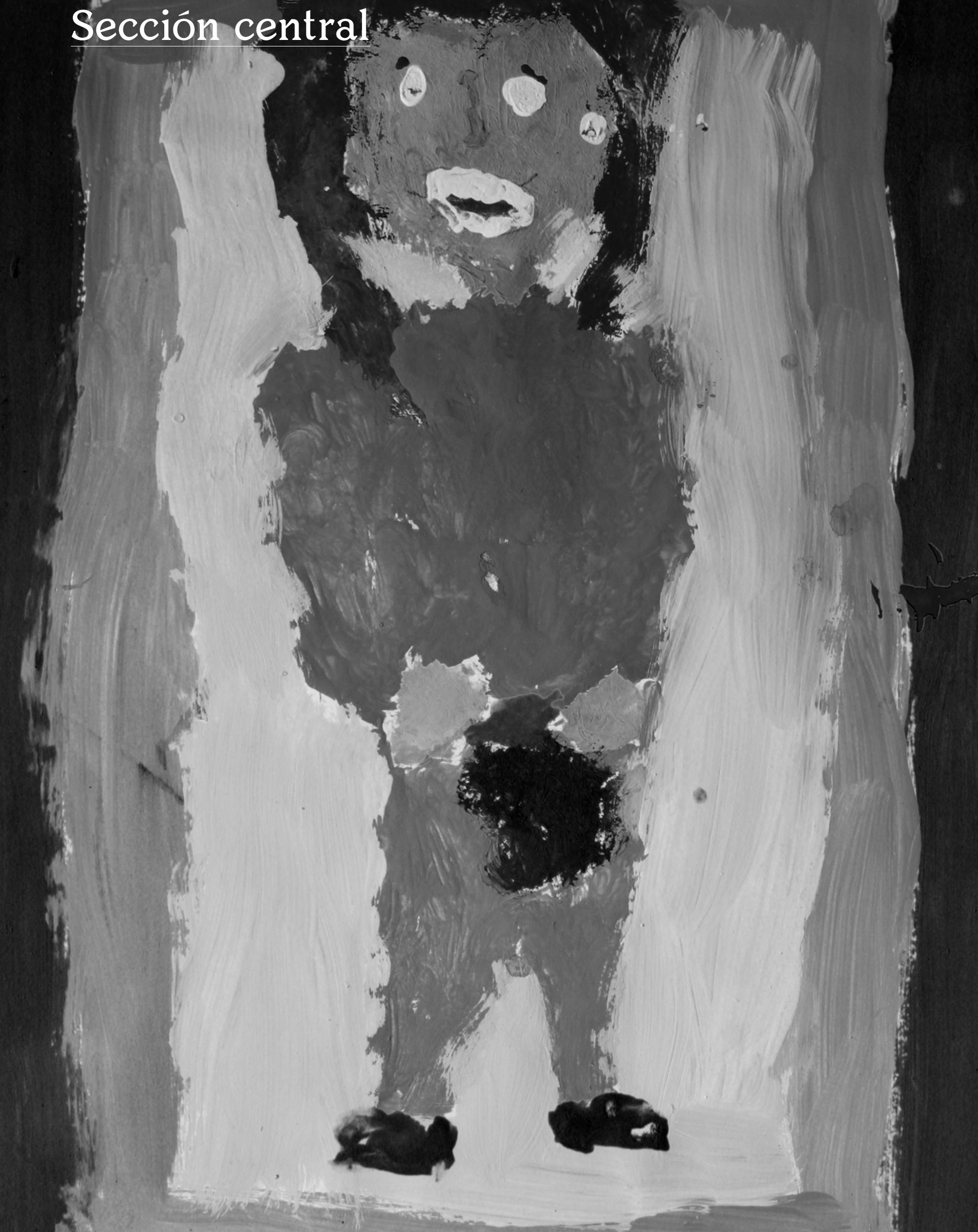




\section{Menstruación: de los imaginarios a la imaginación}

\section{Artículo de investigación}

Recibido: 30 de enero de 2020

Aprobado: 1 de abril de 2020

Stephanny Parra Ordoñez de Valdés

Universidad Pedagógica Nacional, Colombia

stephyp57@hotmail.com

Cómo citar este artículo: Parra Ordoñez de Valdés, Stephanny (2020). Menstruación: de los imaginarios a la imaginación. Estudios Artísticos: revista de investigación creadora, 6(9) pp. 280-292. DOI: https://doi.org/10.14483/25009311.16243

$<$

De la Serie de pinturas estudiantes grado 5. (Bogotá, 2015). Colegio la Toscana Lisboa.

\section{Resumen}

La menstruación y específicamente la menarquía, ha sido considerada a lo largo de la historia, y en diversas culturas, como un hecho trascendental que no solo marca un rasgo biológico en la vida de las mujeres, sino que conecta la feminidad con imaginarios simbólicos que han trascendido de generación en generación, de la mano de mitos, tradiciones y rituales, que se mantienen vigentes $y$ que configuran formas discriminatorias de concebir la menstruación y en consecuencia a las mujeres. Teniendo en cuenta este contexto, en este artículo se plantea un análisis sobre los imaginarios simbólicos de la menstruación en diferentes culturas y momentos históricos, así como su reflexión en el marco de los discursos de un grupo de jóvenes, maestros y maestras del Colegio la Toscana Lisboa, ubicado en la localidad de Suba, Bogotá. Finalmente se esboza una apuesta pedagógica basada en la imaginación y la expresión artística, como camino hacia la resignificación de la menstruación en el escenario escolar.

\section{Palabras Clave}

Cuerpo; menstruación; imaginarios; mujeres; símbolos

\section{(c) (4)}




\section{Menstruation: From Imaginaries to the Imagination}

\author{
Abstract \\ Menstruation, and specifically menarche, has \\ been considered throughout history, and in \\ various cultures, as a transcendental fact that \\ not only marks a biological feature in women's \\ lives, but also connects femininity with symbolic \\ imagery that has transcended from generation to \\ generation, with the help of myths, traditions and \\ rituals, which remain in force and which shape \\ discriminatory ways of conceiving menstruation \\ and, consequently, women. Taking this context \\ into account, this article presents an analysis of \\ the symbolic imagery of menstruation in different \\ cultures and historical moments, as well as its \\ reflection in the framework of the speeches of a \\ group of young adults, teachers from the Colegio \\ La Toscana Lisboa, located in the locality of Suba, \\ Bogotá. Finally, a pedagogical bet based on imagi- \\ nation and artistic expression is outlined, as a path \\ towards the resignification of menstruation on the \\ school stage.
}

\section{Keywords}

Body; menstruation; imaginary; women; symbols

\section{Menstruation : depuis les imaginaires à l'imagination}

\section{Résumé}

La menstruation, et en particulier la ménarche, a été considérée tout au long de l'histoire et dans diverses cultures comme un fait transcendantal qui non seulement marque une caractéristique biologique dans la vie des femmes, mais relie également la féminité à l'imagerie symbolique qui a transcendé de génération en génération, avec l'aide de mythes, de traditions et de rituels, qui restent en vigueur et qui façonnent des façons discriminatoires de concevoir les menstruations et par conséquent les femmes. Compte tenu de ce contexte, cet article présente une analyse de l'imagerie symbolique des menstruations dans différentes cultures et moments historiques, ainsi que sa réflexion dans le cadre des discours d'un groupe de jeunes adultes, enseignants au Colegio La Toscana Lisboa, situé dans la localité de Suba, Bogotá. Enfin, un pari pédagogique basé sur l'imagination et l'expression artistique est esquissé, comme un chemin vers la résinification de la menstruation sur la scène scolaire.

\section{Mots clés}

Corps ; menstruation ; imaginaire ; femmes ; symboles 


\section{Menstruação: dos imaginários à imaginação}

\section{Resumo}

A menstruação e especificamente a menarca, tem sido considerada ao longo da história, e em diversas culturas, como um fato transcendental que não só marca uma característica biológica na vida das mulheres senão que conecta a feminilidade à imaginários simbólicos que transcendem de geração em geração, pela mão de mitos, tradições e rituais, que se mantêm vigentes e que configuram formas discriminatórias de conceber a menstruação e por consequência as mulheres. Tendo em conta este contexto, neste artigo se apresenta uma análise sobre os imaginários simbólicos da menstruação em diferentes culturas e momentos históricos, assim como sua reflexão no contexto dos discursos de um grupo de jovens, professores e professoras do Colégio la Toscana Lisboa, localizado no bairro de Suba, Bogotá. Por fim, é delineada uma aposta pedagógica baseada na imaginação e na experiência artística, como caminho para a ressignificação da menstruação no cenário escolar.

\section{Nukanchi imasa kaska nispak sug rigch: imasa iachakuna kauagtakuna guagüita kai llagtama challamuska}

\section{Maillallachiska}

Kai kilkapi ninakumi imasami warmikunata mana allilla kauankuna guaguita kai alpama chaiamuku warmikunata jiru kauankuna ñugpata Nukanchipa kausapi iachaskakuna warmi puralla chaskiga, kunaura tiami achka iachakuna chasallata munankuna warmikuna iachai kungapa imasamika wambra llukai nispa chasalla wambra llukauramanda kauankuna ukunimanda iachaikungapa nispa kunaura utka pusankuna doctorkuna.

\section{Rimangapa Ministidukuna}

Achka suma rimai ailastimai; warmi wambra llukanpaga; iachakuna wambrita kauangapa; mana allilla kausai sug kuna kauangapa.

\section{Palabras clave}

Corpo; menstruação; imaginários; mulheres;

símbolos 


\section{Introducción}

Los mitos, las leyendas y los imaginarios sociales que rodean la menstruación, han sido desde siempre un elemento vital en la configuración de sentidos a propósito de la feminidad. Para Simone de Beauvoir (1949) "Al igual que el pene extrae del contexto social su valor privilegiado, del mismo modo es el contexto social el que hace de la menstruación una maldición" (p. 139) que se revela en las imágenes y relatos cotidianos en los que mujeres de diferentes edades se ven sometidas al aislamiento y la vergüenza.

Con frecuencia escuchamos que la menstruación es la marca vital, que da inicio a la adultez de la mujer "de niña a mujer", lo que no queda dicho es que esta condición está cargada de simbolismos, en su mayoría negativos que llevan a las niñas a sentir temor de convertirse en mujeres. Lejos de ser una condición que las dignifique, como lo veremos al largo del documento, la menstruación es considerada como una mancha que obstaculiza la vida plena de las mujeres.

Con la intención de identificar cuáles han sido los imaginarios que sostienen parte de los mitos y representaciones sociales que hoy se tienen sobre la menstruación, a lo largo del texto haré una breve revisión documental sobre el tema, que se contrasta con un ejercicio de indagación realizado con estudiantes de grado quinto y octavo del Colegio La Toscana Lisboa, a través de la observación participante en talleres de aula y entrevistas cortas que además incluyeron la opinión de docentes de la institución.

Antes de continuar, es importante señalar que acudimos a la categoría de imaginario simbólico, al considerar que la menstruación, es un concepto cuya significación está vinculada a diversas imágenes que no necesariamente la explican de manera objetiva y racional; contrario a ello están ligadas a lo misterioso, a lo mágico, a cierto tabú que esconde un sentido secreto, una suerte de epifanía.

La menstruación se constituye en un campo simbólico en tensión, prueba de ello son las diferentes palabras y expresiones utilizadas para referirse a este mismo hecho (la regla, el periodo, la luna, entre otras), lo que comprueba su inestabilidad y dinamismo. Para Durand, la imaginación simbólica propiamente dicha, emerge cuando el significado es imposible de presentar y el signo solo puede referirse a un sentido que le resulta escaso y equivoco. De este modo, el dominio predilecto del simbolismo y en este caso de la menstruación, es "lo no-sensible en todas - sus formas; inconsciente, metafísico, sobrenatural y surreal" (Durand, 1968, p. 14).

Siendo plenamente conscientes de las limitaciones que supone la compleiidad del tema a tratar, este documento se plantea como una apertura a la reflexión y el diálogo, que culmina con una apuesta pedagógica que busca, a través de la creación y la imaginación, resignificar e incomodar los símbolos naturalizados de la menstruación, en la búsqueda de instaurar nuevos imaginarios.

\section{Imaginarios simbólicos sobre la menstruación}

El triunfo del signo sobre el símbolo dice Duran, obedece a una lógica cartesiana que se basa en "un método de análisis y de medición matemática, producido por un deseo de enumeración y de observación en el cual desembocará la ciencia histórica" (Durand, 1968, p. 28). Es así, como el símbolo pierde vigencia ante la imposibilidad de asirlo por completo en el signo, su multiplicidad interpretativa se vuelve peligrosa, por lo que se le asigna un lugar de desprestigio epistemológico.

No obstante, esto no quiere decir que la función cohesionadora del símbolo en el plano cultural desaparezca o se vea menguada, contrario a ello, el símbolo, sigue ostentando el acceso a lo trascendente y contribuyendo a la definición de identidades culturales, que, a su vez, revelan el inconsciente colectivo de una sociedad, definiendo sus marcos de posibilidad en un entramado de poderes históricos que van mutando con el paso del tiempo.

Para Durand, las estructuras antropológicas de lo imaginario que dan soporte a las culturas, resultan del análisis de la representación del mundo a través de dos polaridades que ha denominado como 
régimen diurno y régimen nocturno, las cuales operan como un sistema de agrupamiento basado en un dualismo antagónico.

El primer régimen, el diurno, es el tiempo lineal y, también, el reino de la luz y el miedo a las tinieblas, pues éstas son la expresión de la muerte como tiempo final. Es el régimen de Antítesis, de la separación, de la heterogeneidad. El segundo, el Régimen Nocturno, es el tiempo cíclico donde la muerte es asimilada de otra manera, por medio de mitos, rituales o relatos que colocan esta muerte del lado de la iniciación, del aprendizaje, como una parte de la vida. (Franzone, 2005)

Para Bachelard, (citado por Durand, 1968, p. 96 ) "La imaginación se revela como el factor general de equilibración psicosocial" , de ahí que el análisis de los símbolos se enfrente a la ausencia de una pureza concreta, lo que dificulta ubicarlos con facilidad en los regímenes sugeridos por Durand (regimen diurno y nocturno), por lo que se hace necesario recurrir a las redundancias, a las repeticiones de sentido y a la ritualización, como caminos para establecer la naturaleza de cada símbolo.

En lo que sigue del texto, veremos cómo las repeticiones y redundancias acerca de los imaginarios simbólicos sobre la menstruación, la sitúan en un lugar antagónico en relación con su equivalente masculino, "el semen". Para Beauvoir, "Al igual que el pene extrae del contexto social su valor privilegiado, del mismo modo es el contexto social el que hace de la menstruación una maldición" (Beauvoir, 1949, p. 139). La menstruación se constituye en una marca vital femenina ritualizada, que, a diferencia del semen y del propio pene, (simbolizado en la mayoría de las culturas como marca de poder), se explaya en un plexo simbólico amplio y diverso, que conecta con una imagen nociva del flujo menstrual.

Según Durand, el imaginario social occidental relativo a esta concepción nociva de la menstruación tiene una doble raíz socio-histórica: el mundo greco-latino y el sistema de pensamiento judeocristiano (Durand, 1981). En ambos marcos de significación religiosa está presente esta idea del ciclo menstrual, como algo con poder sobrenatural. Sucede lo mismo en gran parte de las comunidades indígenas de las que se conocen rituales y prácticas tradicionales que vinculan la menstruación con fenómenos fantásticos.

Gran parte de los elementos ficcionales que rodean la menstruación, no solo configuran el magma de significación de un aspecto fisiológico en la vida de las mujeres, sino que se revierte sobre las concepciones e imaginarios discriminatorios sobre la feminidad. Cada mujer menstrua en promedio 2520 días a lo largo de su vida, lo que equivaldría a siete años seguidos, tiempo durante el cual es foco de innumerables juicios valorativos que la relegan de la vida pública y la someten al aislamiento.

Llama la atención que en este tránsito de lo público a lo privado, la menstruación haya sido signada de diversas maneras, así lo muestra el estudio de Alarcón (2004) en el que cita las palabras coloquiales de uso diario para referirse a la menstruación, recogidas por Luis Flórez, quien las publicó en uno de los documentos del Instituto Caro y Cuervo.

La colora- da, el consuelo, la cortada del dedo, la corriente, la cosa, la costumbre, la mensual, el chorrito, la cho- rriada, estar chorriando, estar chorriando la piña, el derrame, la diecinueve y doce, estar enferma, estar entiempada, tener la enfermedad del mes, estar a fin de mes, tener el flujo, tener la hemorragia, estar con la luna, estar con la luna brava, estar de luto, estar mala, tener las lluvias, tener el mal de las mujeres, estar con la mensualidad, estar con el mes, tener visita, estar con la mestruel, estar con la demostración, estar con la administración, estar con la postración, estar morajiá, estar pagando arriendo, estar con Pachito, estar con el Chapulín Colorado, estar con el período, estar picada del murciélago, tener la regla, estar con el reglamento, estar con esa bicha, estar con esa jeoda, estar con el reglero, estar con el arreglamiento, estar en remate de mes, estar con la roja, estar en la semana, estar con la soltura, estar con el treinta y jeo, estar con la treinta y una, estar con la veintiuna, estar en esos días. (Flórez, 1969)

Lo que muestra esta variedad de palabras asignadas, es su carácter provisional, magmático (Castoriadis) y flexible que se pliega sobre interpretaciones diversas, en diferentes contextos. Además, refleja un deseo particular de ocultar, de pasar por desapercibido un hecho que para muchas mujeres y para la sociedad en general resulta vergonzoso e indeseable. 
Para Simone De Beauvoir,

La mancilla menstrual la inclina a la mujer hacia el disgusto y el temor. «iHe ahí lo que significan esas palabras: ser mujer!». La fatalidad que hasta entonces pesaba sobre ella confusamente y desde fuera, está agazapada en su vientre; no hay medio de escapar; y se siente acosada. En una sociedad sexualmente igualitaria, no encararía ella la menstruación sino como su manera singular de acceder a su vida adulta; el cuerpo humano conoce en hombres y mujeres muchas otras servidumbres más repugnantes, a las cuales se acomodan fácilmente, porque, siendo comunes a todos, no representan una tara para nadie; las reglas inspiran horror a la adolescente, porque la precipitan a una categoría inferior y mutilada. (Beauvoir, 1949, p. 74)

La fatalidad a la que se refiere Beauvoir, habita el inconsciente de las niñas ante un hecho desconocido del que no obstante se enteran por rumores y mitos ampliamente difundidos en sus círculos cercanos. Son los imaginarios culturales los que devienen en normas y símbolos que crean una representación de mundo (Castoriadis) que para este caso resulta peligrosa.

El primer contacto con la menstruación está cargado de simbolismos asociados a una etapa de iniciación: "convertirse en mujer", lo cual implica una serie de cambios. Durante el ejercicio de indagación realizado con estudiantes de grado octavo y décimo del Colegio La Toscana Lisboa, varias de ellas aseguraron que la menarquía trajo consigo un aislamiento de su comunidad de amigos. Por otra parte, las prácticas cotidianas que realizaban antes fueron abandonadas al considerar que se encontraban en un momento nuevo de sus vidas, además el hecho de estar menstruando constituía un riesgo inminente de mancharse y ser la burla de todos, por lo que durante este periodo preferian mantenerse alejadas:

Antes de que me llegara la menstruación, yo parecía un miquito jugando con mis primos, brincando de un lado al otro, pero después uno ya no puede hacer eso, una vez me manché sin culpa y me la montaron, además como que a uno le deja de gustar. (Estudiante grado décimo). (Parra, 2018, p. 81)

Si pensamos en la menstruación como una categoría vinculada a los imaginarios sociales, resulta fácil entender que este autoaislamiento obedece a una carga simbólica histórica, caracterizada por las diferentes formas de reclusión a las que han sido sometidas las jóvenes en diversas culturas, con el fin de evitar su contacto con la comunidad. Para Durand (1968), una de las características principales del imaginario, es que se encuentra en el inconsciente, para ser más exactos en el inconsciente colectivo situado por Jung, por lo que las acciones vinculadas a cada símbolo resultan en la mayoría de casos carentes de sentido lógico, como es el caso de los aislamientos de las niñas menstruantes.

En Colombia, por ejemplo, uno de los casos más emblemáticos que sigue vigente hasta el día de hoy, es el de las comunidades Wayuu, originarias de la Guajira al norte del país. Según su tradición, cuando a las niñas les viene la menarquía deben participar del páülüjütü o encierro. Citando un texto de Vergara (1997) Alarcón (2005) asegura que en los indígenas Wayuu,

No se destaca la pubertad en los varones, pero las niñas están sometidas a un severo rito de paso. Cuando la muchacha empieza a menstruar, es sometida a un período de reclusión, al término del cual se ha convertido en mujer equipada para casarse. Durante el inicio de esta reclusión, la joven es completa o parciamente rapada y luego instalada en una hamaca colgada cerca del techo de la casa. Durante los días siguientes es cuidada con alimentos vegetales especiales, Ilamados jaguapi, y observa una dieta rigurosa. En ese tiempo la bañan con frecuencia y la instruyen en las tareas femeninas, tejido, hilado, le imparten conocimientos sobre los procesos tradicionales de control natal, embarazo y quizás algunas técnicas eróticas. (Alarcón, 2005, p. 38)

En su obra Los ritos mágicos y trágicos de la pubertad femenina, Gutierre Tibón (1984), narra como el temor a la primera sangre de las niñas, llevó a varias culturas a recluirlas en condiciones poco favorables, como es el caso de una isla al oeste de Nueva Guinea, la Nueva Irlanda; que se les segregaba durante cuatro o cinco años en minúsculas jaulas conservadas en la oscuridad, con absoluta prohibición de que posara los pies en el suelo: así vegetaba la desdichada criatura desde los nueve hasta los trece o catorce años. (...) En la tribu australiana de los Walkelburn la mujer considerada tabú no puede entrar en el campamento por el mismo sendero que los hombres. Una violación a esta ley se 

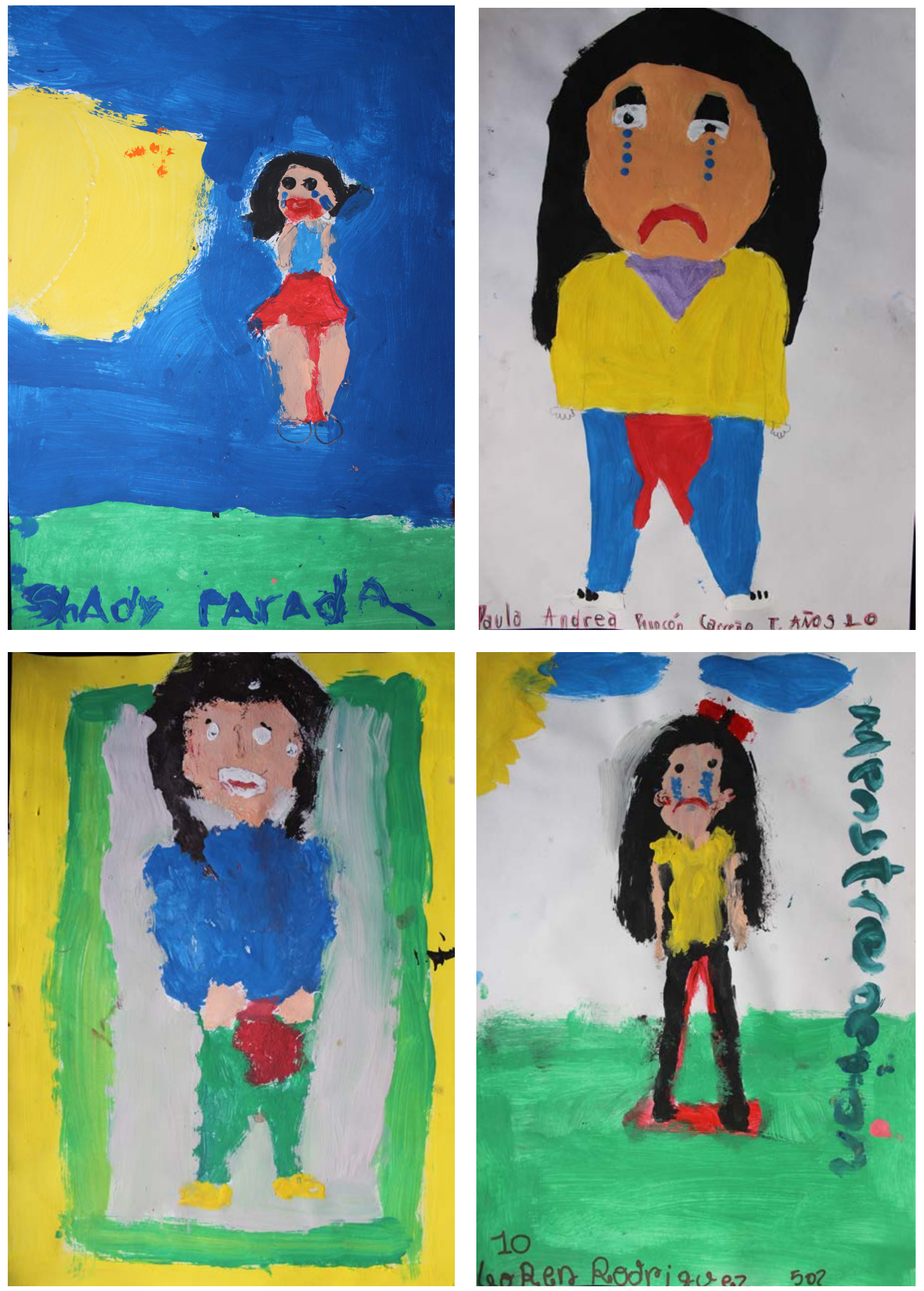

Imagen 1. Serie de pinturas estudiantes grado 5. (Bogotá, 2015). Colegio la Toscana Lisboa. 
castiga con la muerte. (...) (En California). Aquí los indios pensaban que una joven, en su menarquía, estaba poseída de un grado particular de poder sobrenatural; pero con frecuencia se le asociaba con un fuerte poder maligno inherente a su condición. (Tibón, 1984).

Por su parte, en la tradición judeocristiana también se hace mención a la reclusión durante el periodo menstrual:

Cuando la mujer tuviere flujo de sangre, y su flujo fuere en su cuerpo, siete días estará apartada; y cualquiera que la tocare será inmundo hasta la noche. Todo aquello sobre que ella se acostare mientras estuviere separada, será inmundo; también todo aquello sobre que se sentare será inmundo. Y cualquiera que tocare su cama, lavará sus vestidos, y después de lavarse con agua, será inmundo hasta la noche. También cualquiera que tocare cualquier mueble sobre que ella se hubiere sentado, lavará sus vestidos; se lavará luego a sí mismo con agua, y será inmundo hasta la noche. (Lv. 15: 19-23)

Es importante señalar que los argumentos para el aislamiento en todas las culturas revisadas no obedecen a una reflexión teórica e intelectual, quiere decir esto que no existe una razón lógica por la que las mujeres deban aislarse de su comunidad durante su periodo menstrual. No obstante, dado que su definición ha estado cargada de afectos y simbolismos, nos apegamos a la idea plantada por Castoriadis según la cual,

Las significaciones imaginarias sociales crean un mundo propio para la sociedad considerada, son en realidad ese mundo: conforman la psique de los individuos. Crean así una "representación" del mundo, incluida la sociedad misma y su lugar en ese mundo: pero esto no es un constructual intelectual; va parejo con la creación del impulso de la sociedad considerada (una intención global, por así decir) y un humor o Stimmung específico - un afecto o una nebulosa de afectos que embeben la totalidad de la vida social. (Castoriadis, 1997, pp. 9)

A la pregunta ¿Qué te evoca la palabra menstruación? Realizada a estudiantes (mujeres) de grados octavo y décimo a quienes ya les había venido su primera menstruación, más del $80 \%$ respondieron con las siguientes expresiones:
Asco, dolor, miedo, tristeza, susto, sorpresa, impresión, vomito, escalofríos, llanto... de nuevo dolor y un gesto de repulsión. La menstruación, una mancha de sangre, un castigo divino, la prueba del pecado, la sangre que no sirve, el peligro de la gestación, aquello que no se nombra, aquello que se susurra, el miedo de lo desconocido, el temor al repudio, incomodidad, melancolía, inseguridad, indisposición, angustia, secreto, lejanía... Aquello que nos convierte en mujeres. ${ }^{1}$ (Parra, 2018, p.78)

Por su parte, las estudiantes de grado quinto de aproximadamente 8 a 10 años, a quienes no les había venido la menstruación respondieron a la misma pregunta, pero a través de una imagen, las imágenes que más rasgos en común tuvieron fueron las de la serie de pinturas (Imagen 1., página anterior).

Lo que revelan tanto las palabras como las pinturas realizadas por las niñas y jóvenes, es la prevalencia del imaginario nocivo sobre la menstruación. Para Durand, "una imagen simbólica necesita ser revivida sin cesar" (1968, p. 38) Citando a Lévi-Strauss, pone como ejemplo la repetición del mito y de las parábolas evangélicas como "una repetición de ciertas relaciones, lógicas y lingüísticas, entre ideas o imágenes expresadas verbalmente" (p. 13) que llevan a la revelación del misterio, a la aparición de un sentido secreto, a la epifanía.

El símbolo es pues, una representación flexible de múltiples refundaciones tal es el caso de la menstruación y su mitificación que aparece renovada en diversos discursos, para citar un ejemplo bíblico como el de Lévi-Strauss nos referiremos a las palabras de Yahvé a Moisés en el Levítico:

Habla a los hijos de Israel y diles: Cuando dé a luz una mujer y tenga un hijo, será impura durante siete días; será impura como en el tiempo de su menstruación. Al octavo día será circuncidado el hijo, pero ella quedará en casa durante treinta y tres días en la sangre de su purificación; no tocará nada santo ni irá al santuario hasta que se cumplan los días de su purificación. Si da a luz una hija, será impura durante dos semanas, como el tiempo de su menstruación, y se quedará en casa durante sesenta y seis días en la sangre de su purificación. (Lv 12: 1-5)

\footnotetext{
1 Entrevistas a estudiantes de grado octavo y décimo. Colegio La Toscana Lisboa IED. Bogotá, agosto de 2015.
} 
En el Corán, por su parte, el símbolo se repite de la siguiente forma:

Te preguntan acerca de la menstruación. Di: “Es un mal imanteneos pues aparte de las mujeres durante la menstruación y no os acerquéis a ellas hasta que se hayan purificado! Y cuando se hayan purificado, id a ellas como Alá os lo ha ordenado". Quien teme a Alá, él le facilita sus cosas. (Verso 2.222)

En el siglo XVII, Plinio el viejo, escritor y científico, nacido en lo que hoy conocemos como Italia, escribió en una de las obras más importantes del enciclopedismo "Naturalis historia", lo que sus estudios le habían revelado sobre la menstruación:

Pero no encontraremos difícilmente nada más prodigioso que el flujo menstrual. La proximidad de una mujer en este estado hace agriar el mosto; a su contacto, los cereales se convierten en estériles, los injertos mueren, las plantas de los jardines se secan, los frutos de los árboles donde ella está sentada caen; el resplandor de los espejos se enturbia nada más que por su mirada; el filo del acero se debilita, el brillo del marfil desaparece, los enjambres de las abejas mueren; incluso el bronce y el hierro se oxidan inmediatamente y el bronce toma un olor espantoso; en fin, la rabia le entra a los perros que prueban de dicho líquido y su mordedura inocula un veneno sin remedio. Hay más: el asfalto, esa sustancia tenaz y viscosa que, a una época precisa del año sobrenada un lago de Judea, que se llama Asphaltites, no se deja dividir por nada, pues se adhiere a todo lo que toca, excepto por un hilo infectado por este veneno. Se dice incluso que las hormigas, esos animalejos minúsculos, le son sensibles: ellas echan los granos que transportan y no los vuelven a recoger. Este flujo tan curioso y tan pernicioso aparece todos los treinta días en la muier, y, con más intensidad todos los tres meses (Hist. Nat., VII, pp. 64-66)

Ahora bien, al contrastar estas definiciones con algunos mitos vigentes para jóvenes, maestros y maestras participantes de la indagación, nos encontramos las siguientes afluencias: Por un lado el imaginario de la impureza y periuicio a terceros durante la menstruación, explícito en mitos como:

Durante la menstruación las mujeres no deben regar las plantas porque las dañan; la mujeres con menstruación no deben alzar a los niños recién nacidos porque pueden enfermarlos; no es bueno que una mujer con la menstruación te corte el cabello porque puede achilarlo; lo mejor es que las mujeres no se bañen durante la menstruación y en lo posible permanezcan en casa. ${ }^{2}$

\section{De los imaginarios a la imaginación}

Parafraseando a Durand, somos hijos/as de una civilización racionalista y positivista, que se ha empeñado en hacer labor iconoclasta, que no obstante y pese a su esfuerzo ha fracasado. Los símbolos siguen configurando las culturas, "Pero, asimismo, la potencia de figuración de las figuras, la interpelación de los emblemas, de las alegorías, de las simples palabras, con toda su carga de evocación poética, exigen irrevocablemente otra interpretación" (Durand, 1968, p. 121).

Lo que he mostrado a lo largo del documento, es la relevancia de los imaginarios simbólicos a propósito de la menstruación en las formas de interpretación y de vivencia de estas por parte de las jóvenes. Lo que no queda suficientemente dicho es su impacto negativo en la configuración de la feminidad. Si el momento de convertirse en mujeres está marcado por el hecho biológico de menstruar, y este último, es un hecho históricamente cargado de simbolismos nocivos, sin duda la noción de "ser mujer" comporta de entrada una condición de desigualdad.

Sabiendo la complejidad de la pretensión de instaurar nuevos imaginarios que redistribuyan los lugares de poder y generen un nuevo equilibrio simbólico, nos planteamos siguiendo a Castoriadis la necesidad de interpretar el imaginario como:

No causal, como un comportamiento que no solo es imprevisible sino creador (de individuos, grupos, clases o sociedades enteras) no se presenta como una mera desviación de un tipo existente sino como planteamiento de un nuevo tipo de comportamiento, como institución de una nueva regla social... en síntesis, como algo que surge o se produce y no se puede deducir de la situación precedente, como conclusión que supera las premisas o como postulación de premisas nuevas. (Poirier, 2005, p. 62)

De este modo acudimos a la imaginación y su expresión artística para hacer lo que Durand ha denominado la remitización, "es decir, recolección

2 Resultado de las entrevistas realizadas a estudiantes, maestras y maestros en julio de 2015. 
del sentido, colectado, cosechado, en todas sus redundancias y vivido de pronto por la conciencia que lo medita en una epifanía instaurativa, que constituye el mismo ser de la conciencia" (Durand, 1968, p. 119).

A través de la experiencia artística y pedagógica "De la discriminación a la contemplación" nos proponemos entonces, remitizar la menstruación por medio de la experiencia estética en el sentido rancieriano (Ranciére, 2009), que configura formas sensibles y marcos materiales que transforman, en este caso, el contexto escolar y que más allá de hacer una alusión a lo bello, busca tal como lo anota el mismo autor, develar esa verdad sensible que configura la sociedad, y que lo hace en buena medida de forma no evidente. Este ejercicio busca poner en diálogo la experiencia sensitiva de comunidad educativa en un escenario de intercambio de ideas, imaginarios y evocaciones que se vuelven metáfora y metonimia en un cuerpo femenino, mi cuerpo.

La experiencia se viste de útero y recrea la interpretación de un fenómeno invisibilizado, oculto, en el que se transita de lo público a lo privado y en el que se superponen las relaciones entre lo individual y lo colectivo. El uso de la metáfora del útero y la vagina como escenario material de evocación, reflexión y cuestionamiento, es para este montaje en palabras de Castro "el verbo animado, la acción carnal, ilusión, vivencia de la transformación".

La entrada a la tradicional aula de clases intervenida por la obra plástica de una gran vagina es una entrada al mundo de la imaginación que se nutre de los resultados obtenidos durante esta investigación y que a su vez plantea una reflexión profunda sobre la producción de conocimiento sobre la menstruación, ya no como la mera información de un fenómeno biológico ajeno y distante, sino como una experiencia sensitiva, estética e íntima.

Las imágenes y relatos descritos en los ejercicios de aula y a través de las entrevistas muestran que la menstruación es una experiencia visual. Su definición y representación surgen como un intento de dar significado a aquello que experimenta el cuerpo femenino durante ciertos periodos de tiempo a lo largo de su vida y del que se tiene principal fuente de conocimiento a través de una experiencia esencialmente simbólica.

El cuerpo femenino después de la menarquía queda capturado, inmovilizado, manchado con sangre. Aquellas actividades que otrora fueron dignas de niños y niñas ahora serán restringidas para los cuerpos sensibles y delicados de mujeres adultas.

Es así como en el centro del montaje, de mi útero, yace un cuerpo vaciado, resultado de la privación y el silencio. Un cuerpo blanco hecho de yeso, un cuerpo sangrante, un cuerpo menstruante que dibuja gota a gota la escritura de una corporalidad ajena y distante. Un cuerpo que se toma el centro del aula para mostrar su existencia viva, para recordarnos la existencia de cuerpos femeninos que habitan la escuela sin ser reconocidos.

Finalmente, veintiocho fotos, veintiocho flores, veintiocho tomas, veintiocho días. La ruta que guía el camino por el ciclo menstrual a través de mi lente, de mi cuerpo. Cuatro colores, diferentes tonos, cuatro etapas, sensaciones que cambian de un color a otro. El adentro, yo. La metáfora en su mayor expresión, lo indecible hecho color, hecho imagen.

Una invitación a la ruptura, a desnaturalizar lo asqueroso y volverlo armonioso. Una puerta a la imaginación y a la deconstrucción y reconstrucción social desde lo sensitivo. En palabras de Castro citando a Milán, el retorno de la metáfora a "su función original y crítica: el desenmascaramiento del mundo de la apariencia, inventando a la vez una realidad distinta, más cercana al origen fundacional de las palabras".

En ultimas, se trata de un esfuerzo por decir, por denunciar, un ejercicio que continúa escribiéndose y del cual no hay conclusiones absolutas, solo aproximaciones a una parcela de la realidad de niños, niñas, hombres y mujeres que transitan la escuela despojados de sus propios cuerpos; se trata de "aprovechar la imaginación es ser capaces de romper con lo que está supuestamente fijado y terminado, con lo objetivo y automáticamente real" (Greene, 2005). 

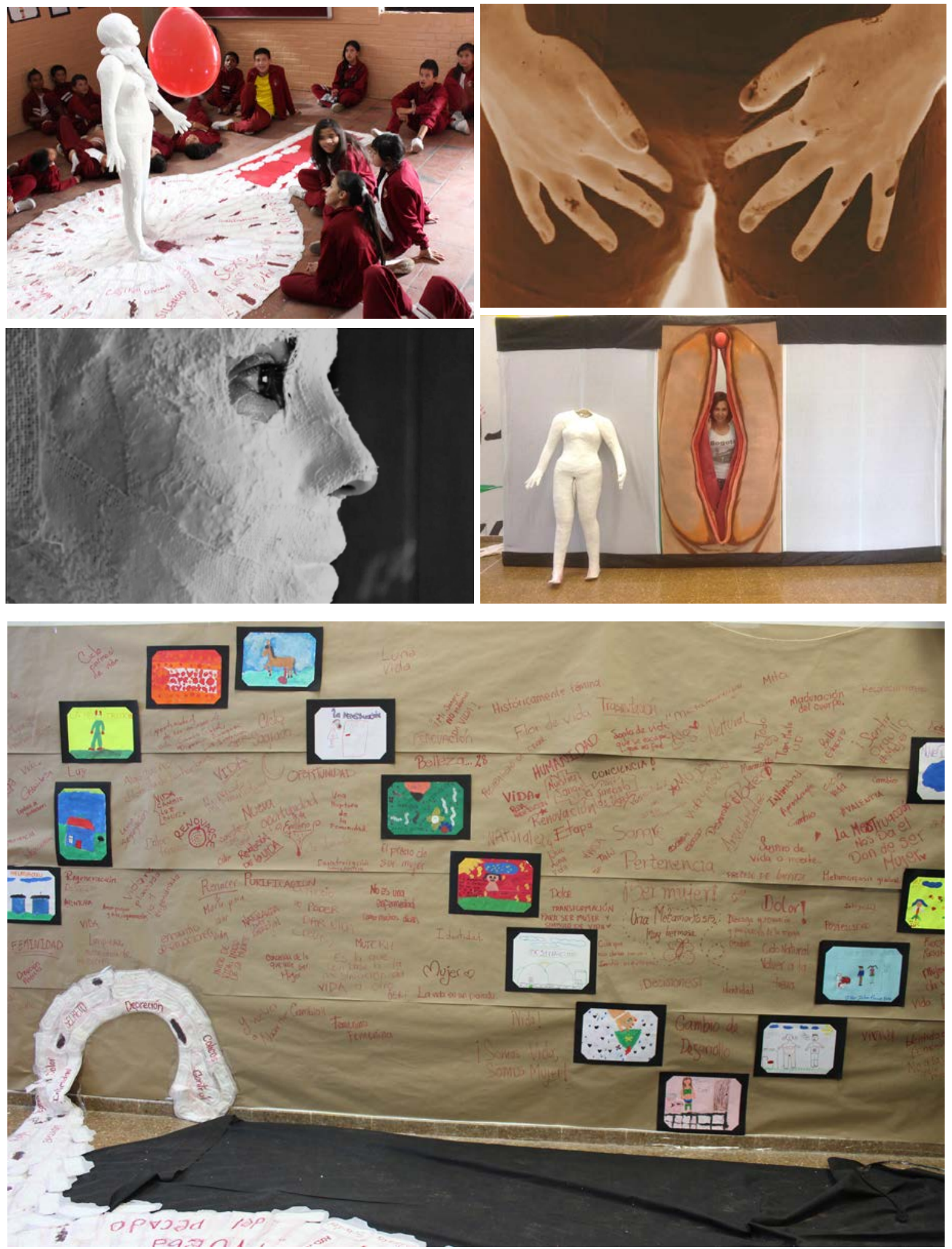

Imagen 2. De la discriminación a la contemplación: Una experiencia estética de la menstruación en la escuela. (Instalación, abril 2016). Proyecto UAQUE Universidad Distrital Francisco José de Caldas. Fotografías: Archivo propio. 


\section{Referencias}

Alarcón, M. (2004). Algunas consideraciones antropológicas y religiosas alrededor de la menstruación, Revista Colombiana de Obstetricia y Ginecología, 56(1),pp. 35-45. "https://doi.org/10.18597/rcog.557"

Durand, G. (1968). La imaginación simbólica. Buenos Aires, Argentina: Amorrortu Editores.

Flórez L. (1969). Léxico del cuerpo humano en Colombia. Bogotá: Instituto Caro y Cuervo.

Franzone, M. (2005). Para pensar lo imaginario: una breve lectura de Gilbert Durand, Alpha (Osorno), (21), pp. 121-137. Disponible en "https://doi.org/10.4067/ S0718-22012005000100008"

Green, M. (2005). Liberar la imaginación: Ensayos sobre educación, arte y cambio social. Barcelona: Ed. Graó.

Parra, S. (2018). UAQUE: el arte de con-vivir. Apuestas investigativas, pedagógicas y estéticas desde la escuela. Bogotá: Investigaciones IDEP.

Poirier, N. (2005). Castoriadis: El imaginario radical. Buenos Aires, Argentina: Ediciones Nueva Visión.

Ranciére. J. (2009). El reparto de lo sensible: estética y política. (Trad.) Cristóbal Durán et al., Santiago de Chile: Ed. LOM.

Tibón, G. (1984). Los ritos mágicos y trágicos de la pubertad femenina. México: Editorial Diana. 